\title{
Methicillin Resistance in Staphylococcus aureus: A Review of the Molecular Epidemiology, Clinical Significance and Laboratory Detection Methods
}

\author{
Résistance à la méthicilline chez Staphylococcus aureus: Une revue de l'épidémiologie moléculaire, la \\ signification clinique et de laboratoire Méthodes de détection
}

\begin{abstract}
BACKGROUND: Despite the volume of knowledge, enhanced surveillance and infection control measures adopted by health care institutions to address the endemicity and frequent disease outbreaks by methicillin-resistant Staphylococcus aureus (MRSA) in hospitals and health care facilities worldwide, infections due to this organism are still responsible for about $50 \%$ of hospital acquired S. aureus infections, with increasing morbidity and mortality.

OBJECTIVE: To provide regional clinicians with current information on the molecular epidemiology, laboratory detection and clinical aspects of MRSA.

METHODS: A review of published literatures on MRSA in Medical Libraries and bibliographic citations on PubMed, Medline and Africa Index Medicus on molecular epidemiology and clinical diseases caused by MRSA and the assessment of the recent laboratory diagnostic approaches.

RESULTS: This review showed that there has been intercontinental spread of some highly pathogenic clones of MRSA threatening to create public health hazard of unprecedented proportion, with the greatest challenge to mankind, being the development of resistance to multiple antibiotics, which in recent times had included resistance to vancomycin and other glycopeptides, the only antibiotic group effective against it. Added to this burden is the emergence of more virulent strains of community-associated MRSA (CAMRSA) which at the turn of the century, has been increasingly reported to cause infections and outbreaks in populations without predisposing risk factors, with attendant high morbidity and mortality.

CONCLUSION: There is need for active MRSA surveillance by healthcare institutions in Africa to identify potential outbreaks, and vigilance in the enforcement of infection control measures such as rational prescription of antibiotics, handwashing, disinfection and sterilization that can limit the emergence and spread of more resistant clones of MRSA. WAJM 2009; 28(5): 281-290.
\end{abstract}

S. S. Taiwo

Keywords: Methicillin-resistance; molecular; epidemiology; assessment; diagnostic approaches.

\section{RÉSUMÉ}

CONTEXTE: En dépit du volume de connaissances, une surveillance accrue et le contrôle des infections mesures adoptées par les établissements de soins de santé pour traiter le caractère endémique et d'épidémies fréquentes de la méticilline-resistant Staphylococcus aureus (MRSA) dans les hôpitaux et les établissements de soins de santé les infections, dans le monde entier en raison de cet organisme sont encore responsable d'environ 50\% des infections nosocomiales à $S$. aureus, avec des taux croissants de morbidité et de mortalité. OBJECTIF: fournir aux cliniciens des informations régionales actuelles sur l'épidémiologie moléculaire, la détection en laboratoire et les aspects cliniques de SARM.

MÉTHODES: Une revue des littératures publié le SARM dans les bibliothèques médicales et des citations bibliographiques sur PubMed, Medline et d'Afrique Index Medicus sur l'épidémiologie moléculaire et clinique des maladies causées par le SARM et l'évaluation du laboratoire des dernières approches diagnostiques.

RÉSULTATS: Cet examen a montré qu'il ya eu propagation intercontinentale de certains clones hautement pathogène du SARM menaçant de créer des risques de santé publique de proportion sans précédent, avec le plus grand défi pour l'humanité, étant le développement de la résistance à plusieurs antibiotiques, qui ces derniers temps, avait inclus résistance à la vancomycine et les glycopeptides autres, le seul groupe antibiotique efficace contre elle. Ajouté à cette charge est l'émergence de souches plus virulentes de SARM-AC (CA-MRSA) qui, au tournant du siècle, a été signalé de plus en plus de provoquer des infections et des épidémies dans les populations sans facteurs de risque prédisposants, avec des taux élevés de morbidité et de préposé la mortalité.

CONCLUSION: Il est nécessaire pour la surveillance active de SARM par les établissements de soins de santé en Afrique afin d'identifier les foyers potentiels, et de vigilance dans l'application des mesures de contrôle des infections telles que la prescription rationnelle des antibiotiques, lavage des mains, la désinfection et la stérilisation qui peut limiter l'émergence et la propagation des plus résistants clones de SARM. WAJM 2009; 28 (5): 281-290.

Mots-clés: résistance à la méthicilline; épidémiologie moléculaire; l'évaluation, des approches de diagnostic.

Department of Medical Microbiology and Parasitology, College of Health Sciences, Ladoke Akintola University of Teaching Hospital. P.M.B. 4400, Osogbo, Nigeria

Email:samtaiwo2003@yahoo.com

Abbreviations: ACME, Arginine catabolic mobile element; CA-MRSA, Community associated methicillin resistance staphylococcus aureus; CC, Clonal complex; CCRA, Cassette chromosome recombinase gene; COA, Coagulase; DNA, Deoxyribonucleic acid; HA-MRSA, Health care associated methicillin resistance staphylococcus aureus; MIC, Minimum inhibitory concentration; PFGE, Pulse field gel electrhoresis; MLST, Multilocus sequence tying; MRSA, Methicilin-resistance staphylococcus aureus; MSA, Mannitol salt agar; MST, Multilocus sequence typing; PCR, Polymerase chain reaction; PFGE, Plasmid fingerprinting to pulse field gel electrphoresis; REAP, Restriction enzyme anaysis of plasmid; SPA, Staphylococcus protein A; SSMAC, Soft salt mannitol agar cloxacillin; ST, Sequence type; SSTI, Skin and soft tissue infections; VISA, Vancomycin intermediate staphylococcus aureus 


\section{INTRODUCTION}

Staphylococcus aureus is a nonmotile, aerobic or facultatively anaerobic Gram positive coccus that inhabits the nasal membranes and skin of warm blooded animals, in whom it causes a range of infections from mild, such as skin infections and food poisoning, to lifethreatening, such as pneumonia, sepsis, osteomyelitis and infectious endocarditis. ${ }^{1}$ In the pre-antibiotic era, the rate of mortality from invasive $S$. aureus disease was high and the introduction of penicillin into the market had a dramatic impact on treatment. Shortly after the introduction of penicillin and its widespread use as a chemotherapeutic agent, strains of $S$. aureus resistant to penicillin through the production of $\beta$-lactamase (penicillinase), an enzyme that destroy the $\beta$-lactam ring of penicillin, emerged. Methicillin, a semisynthetic penicillin, was introduced in 1959 to overcome the problems that arose from the increasing prevalence of penicillinase-producing strains of $S$. aureus. Within a very short time, strains of $S$. aureus resistant to methicillin rapidly emerged ${ }^{2}$ and became a major clinical problem within hospitals in Europe in the $1960 \mathrm{~s}^{3}$ and in the United States in the $1970 \mathrm{~s}^{4}$ and since then in several countries of the world. ${ }^{5}$

Resistance to methicillin is conferred on $S$. aureus by the acquisition of a mecA gene $^{6}$ which has recently been localized within a large $(52-\mathrm{kb})$ DNA cassette designated staphylococcus cassette chromosome mec (SCCmec) inserted in the bacterial chromosome. ${ }^{7}$ The mecA gene encodes a $\beta$-lactam insensitive cell wall synthesis enzyme called penicillin binding protein 2a or 2' (PBP 2a or PBP 2'), a $78 \mathrm{kD}$ protein with low affinity for $\beta$-lactam agents. ${ }^{8}$ The SCCmec is known to contain additional genes conferring resistance to aminoglycosides, bleomycin and macrolide-lincosamide-streptograninB $\left(\mathrm{MLS}_{\mathrm{B}}\right)$ groups of antibiotic. ${ }^{9}$ Acquisition of SCCmec therefore provides $S$. aureus with array of resistance genes that make it the most resistant pathogenic organism in hospital acquired infections.

World wide, MRSA now comprise up to $50 \%$ of $S$. aureus isolates in hospitals ${ }^{10}$, and is involved in surgical wound infections, nosocomial pneumonias, bacteraemias and other forms of infections. Treatment options have been severely restricted to potentially toxic antimicrobials such as vancomycin and other glycopeptides, ${ }^{11}$ leading to increasing mortality, morbidity and costs. ${ }^{10}$ In the 1980s, MRSA emerged as a community-acquired pathogen causing infections in people without identifiable established risks. ${ }^{12}$ These community-acquired MRSA infections, which were first noticed among intravenous drug addicts, have in recent times become increasingly being reported among infants and children, ${ }^{13}$ and among individuals involved in intense contact sports $^{14}$ with attendant morbidity and considerable mortality.

Over the years, there has been improvement in diagnostic methodology of MRSA, particularly the phenotypic detection of hetero-resistant strains, using conventional antimicrobial susceptibility testing such as the methicillin/oxacillin disk diffusion, cefoxitin disk diffusion, broth microdilution, oxacillin agar screen, population profile analysis, oxacillin and cefoxitin E-test and many automated methods. ${ }^{15,16}$ Molecular detection of mecA gene using DNA probe or its products PBP 2' by immunoblot assay and PCR based methods are now considered the 'gold' standard for MRSA confirmation. ${ }^{17}$ Epidemiological typing methods to characterize MRSA strains involved in outbreaks have also moved from the use of bacteriophage typing, protein antigen electrophoresis profile and plasmid fingerprinting to pulse field gel electrophoresis (PFGE) of SmaI-digest of genomic DNA, ribotyping, multilocus sequence typing (MLST), PCR amplification of target genes such as staphylococcus protein A ( spa) and coagulase ( $\mathrm{coa}$ ) genes, and more recently sequencing of these DNA. ${ }^{18}$

From published literatures available, MRSA reporting in Nigeria and other parts of Africa appear very few. Does this imply that MRSA occurence is low in Africa, and the continent is therefore not at risk of the global threat posed by MRSA? This review is intended to provide clinicians, most especially those in developing countries of Africa, up-to- date information on the molecular epidemiology, clinical significance and laboratory detection methods of MRSA, and the need for increased surveillance of infectious diseases especially those caused by MRSA.

\section{EPIDEMIOLOGY OFMRSA}

\section{Historical perspectives}

The strain of Staphylococcus aureus resistant to methicillin was first detected in England in $1960^{2}$ following the introduction of methicillin (the prototypal penicillinase resistant penicillin) in 1959. These strains were encountered steadily across the UK and Europe during the decade but their clinical significance was overlooked. By the late 1960s however, an unusual increase in the frequency of clinically significant isolates in Britain occurred ${ }^{3}$ and by the turn of that decade, they had become recognized as nosocomial pathogens in the UK and across Europe. During this period, few sporadic cases and epidemic outbreaks of MRSA were reported in the United States but by 1975 , nosocomial MRSA infections in United States hospitals were widely reported. ${ }^{4}$ In the 1980s, MRSA infections were reported in persons who had no previous hospitalization. ${ }^{12}$ These infections appeared to be acquired in the community and were termed community-acquired MRSA (CA-MRSA) infections. Both healthcare-associated MRSA (HAMRSA) and CA-MRSA infections have since been reported worldwide. ${ }^{5}$

\section{Health Care Associated - MRSA (HA-MRSA) infections}

Since the emergence of MRSA as a major nosocomial pathogen in 1960s, increased isolation rates of HA-MRSA from infected and colonized body parts have been reported in many parts of the world including Africa. ${ }^{5,10,19}$ Recent figures show that infections due to MRSA are responsible for $50 \%$ of hospital acquired $S$. aureus infections with increasing morbidity and mortality ${ }^{10}$ and in some areas, $>50 \%$ of $S$. aureus bacteraemias are caused by MRSA. ${ }^{20}$ Risk factors for MRSA infections include 
recent surgery or hospitalization, residence in a long-term care facility, presence of a percutaneous device or indwelling catheter or recent dialysis. Factors associated with nosocomial acquisition of MRSA include length of hospital stay, previous administration of antimicrobial therapy and significant hospital reservoirs such as colonized and infected patients, hospital personnel and inanimate environment, which are capable of transmitting organisms and causing outbreaks.

HA-MRSA strains are resistant to most other classes of antimicrobial agents and are susceptible only to glycopeptides and new investigational drugs. In 1997, the first strain of MRSA (Mu50) with reduced susceptibility to vancomycin (vancomycin intermediate Staphylococcus aureus; VISA, vancomycin $\mathrm{MIC} \leq 8 \mathrm{mg} / \mathrm{L}$ ) was isolated from a surgical (sternal) wound infection of a four-month old Japanese infant who underwent heart surgery for pulmonary atresia in $1996 .{ }^{21}$ However, the first infection with vancomycin intermediate Staphylococcus aureus (VISA) appeared to have occurred in France in November 1995 in a two-year old girl with leukaemia and a central line-associated bacteraemia successfully treated with surgical drainage and quinupristin-dalfopristin. ${ }^{22}$ Since then, there have been few dozen strains of hetero-resistant VISA (hVISA) and VISA (vancomycin MIC 4-8 mg/L) isolated mainly from patients who were treated with vancomycin for prolonged periods of time. ${ }^{23}$ By 2006, four cases with infections due to vancomycin resistant Staphylococcus aureus (VRSA, vancomycin MIC > $16 \mathrm{mg} / \mathrm{L}$ ) exhibiting
vanA gene complex found in vancomycin resistant enterococci have been confirmed. ${ }^{24}$ So far, two studies from one centre in Nigeria ${ }^{25,26}$ have reported $57.7 \%$ (56 of 97 ) and $86 \%$ (43 of 50 ) of staphylococcal clinical isolates to be vancomycin resistant (using disk diffusion test with $30 \mu \mathrm{g}$ vancomycin). Although vancomycin disk diffusion test used in these Nigerian studies is not a sensitive method of detecting vancomycin resistance, the figures reported may be underestimate of the prevalence of vancomycin resistance among $S$. aureus isolates in Nigeria.

\section{Community associated-MRSA (CA- MRSA) infections}

CA-MRSA was first identified in the United States among intravenous drug users in the early 1980s followed by other high-risk populations such as prison inmates and athletes. At the turn of the 20th century, hospitals in the United States ${ }^{13,14}$ and elsewhere ${ }^{25}$ started noting an increasing trend in the number of CAMRSA infections seen in young, healthy populations without predisposing risk factors. CA-MRSA infections have so far been reported among infants and children ${ }^{13}$ and outbreaks have been reported among individual involved in intense contact sports such as rugby, wrestling, football and soccer. ${ }^{14,26}$

\section{Epidemiology of MRSA in Nigeria}

Although strain of Staphylococcus aureus resistant to methicillin was first detected in England in 1960², it was not until 1987 that Rotimi et $\mathrm{l}^{27}$ gave the first documentation of MRSA in Nigeria; $50.6 \%$ (42 of 83 ) of $S$. aureus the

\section{Table 1: Major differences between HA-MRSA and CA-MRSA}

\begin{tabular}{lll}
\hline Factor & $\begin{array}{l}\text { Health care associated } \\
\text { MRSA }\end{array}$ & $\begin{array}{l}\text { Community associated } \\
\text { MRSA }\end{array}$ \\
\hline Type of Infection & $\begin{array}{l}\text { Predominantly cause skin } \\
\text { and soft tissue infection }\end{array}$ & $\begin{array}{l}\text { Usually cause deep seated } \\
\text { or systemic infection }\end{array}$ \\
Degree of resistance & Usually multiply resistant & $\begin{array}{l}\text { Often susceptible to other } \\
\text { non } \beta \text {-lactam drugs }\end{array}$ \\
SCCmec & Carry a type I, II or III SCCmec & Carry a type IV or V SCCmec \\
PVL genes & Usually does not carry & $\begin{array}{l}\text { Typically carry PVL genes } \\
\text { lukS and lukF })\end{array}$ \\
\hline
\end{tabular}

$P V L=$ Panton-Valentine Leukocidin investigators isolated from clinical specimens in Lagos University Teaching Hospital were resistant to methicillin $(5 \mu \mathrm{g}$ methicillin disk). Since then, there have been dozen reports of MRSA from tertiary health institutions in different regions of Nigeria such as Ibadan $^{28}$ (broth dilution test), $\operatorname{Jos}^{29}$ (Bauer Kirby/NCCLS disk diffusion susceptibility with 1ìg oxacillin disk), Zaria ${ }^{25,26}$ (Bauer Kirby/NCCLS disk diffusion susceptibility with $5 \mu \mathrm{g}$ methicillin or $1 \mu \mathrm{g}$ oxacillin disk), Ilorin ${ }^{30}$ (Bauer Kirby/NCCLS disk diffusion susceptibility with 5ìg methicillin disk) and very recently Osogbo. ${ }^{31}$ All MRSA isolates reported by these researchers were sensitive to vancomycin (disk diffusion with $30 \mu \mathrm{g}$ vancomycin or vancomycin broth dilution) with the exception of the studies by Olayinka et $a l^{25}$ and Onolitola et $a l^{26}$ who reported $57.7 \%$ and $86 \%$ vancomycin intermediate resistance rates respectively among staphylococcal isolates from symptomatic and healthy adults in northern region of Nigeria.

In Nigeria, there are no systematic ways of reporting infectious diseases. Most health institutions lack proper infection control programmes and there are no coordination of efforts among public health authorities. There is hence no national policy for screening, reporting and control of MRSA outbreaks. Only few institutions, as reported above, carry out limited survey of MRSA, which is usually not sustained because of lack of institutional support (personal communication).

All but one of the institutions used disk diffusion test on Mueller-Hinton agar with $5 \mu \mathrm{g}$ methicillin or $1 \mu \mathrm{g}$ oxacillin to screen for methicillin resistance. Although methicillin 5 $\mu \mathrm{g}$, nafcillin 1ìg and oxacillin $1 \mu \mathrm{g}$ disks have been successfully used to screen for methicillin resistance in S. aureus, oxacillin probably gives the best standardized and reliable result for disk diffusion test because of its stability. Because standard inoculum disk diffusion test with oxacillin 1ìg disk may not detect some hetero-resistant strains of MRSA, the tendency is underreporting of the true prevalence of MRSA from these surveys. Adding to this problem is the fact that there is no reference laboratory in Nigeria where 
MRSA isolated through screening/ surveillance can be confirmed genetically and assigned to clonal group. The implication is that MRSA infections/ outbreaks in Nigeria are largely undetected and their contributions to mortality, morbidity and cost of care, associated with hospital-acquired infections are unknown.

\section{Molecular Basis of Methicillin Resis- tance in Staphylococcus Aureus}

As far back as 1975, Sjostrom et al had demonstrated by transformation experiment that the gene (called mec $A$ ) encoding PBP 2a or PBP 2' responsible for methicillin resistance was located on a portion of $S$. aureus chromosome called mec determinant. In 1986, the mecA gene was cloned from a Japanese MRSA strain and its sequence was determined..$^{32}$ This gene was found to be widely distributed among $S$. aureus as well as coagulase negative staphylococci. It was hence speculated that the mec determinant must be freely transmissible among staphylococcal species. However, with a detailed epidemiological study, Kreiswirth et $a l^{33}$ proposed that MRSA originated from a single or two ancestral clones. This led to the view that the frequency of inter or intra species transmission of mec $A$ is a rather limited process and that mec transmission may not be due to specialized transmission machinery such as a transposon.
In 1999, mecA gene of $S$. aureus strain N315 (MRSA isolated in 1982 from pharyngeal smear of a Japanese patient) was shown to be localized within a large (52-kb) DNA cassette designated staphylococcus cassette chromosome mec (SCCmec) inserted in the chromosome. By sequence determination of the entire DNA of the SCCmec, ${ }^{7}$ two novel genes designated staphylococcal cassette chromosome recombinase genes ( $c r r A$ and $c c r B$ ) encoding polypeptides, CcrA (449 amino acids) and CcrB (542 amino acids) having partial homology to recombinases of the invertase/resolvase family were described. These recombinases were found to catalyze precise excision of SCCmec from MRSA chromosome and its site/sequencespecific integration into $S$. aureus chromosomes when introduced into cells as a recombinant multicopy plasmid.

The whole genome sequencing of MRSA N315 strain and another related strain, Mu50 (an MRSA strain with vancomycin intermediate resistance, VISA, isolated in 1997 from the pus of a Japanese male baby with a surgical wound infection that did not respond to vancomycin), were done in 2001..$^{9}$ The resistance island $\mathrm{SCCmec}$ was found to contain in addition to $m e c A$ and $c c r$ genes, additional genes encoding resistance to other antibiotics making $S$. aureus the most resistant pathogenic organism in hospital acquired infections. Using

Table2: Gene complex of the SCCmec element of MRSA

\begin{tabular}{|c|c|c|}
\hline Gene Complex & Specific Genes & Gene Product \\
\hline $\begin{array}{l}\text { ccr gene complex } \\
\text { mec gene complex }\end{array}$ & $\begin{array}{l}\text { ccr genes, ORF } \\
\text { smecA gene } \\
\text { regulatory genes, } \\
\text { insertion sequence (IS) }\end{array}$ & $\begin{array}{l}\text { CcrA (449aa), CcrB (542aa), CcrC } \\
\text { PBP2a or PBP2' }\end{array}$ \\
\hline \multirow[t]{5}{*}{$\begin{array}{l}\mathrm{J} 1-\mathrm{J} 3 \text { region } \\
\text { (non-essential) }\end{array}$} & bleO gene & $\begin{array}{l}\text { Bleomycin resistance protein } \\
\text { O-nucleotidyltransferase } 4 \\
\text { (aminoglycoside modifying enzyme) }\end{array}$ \\
\hline & ant (4') gene & \\
\hline & $k d p$ operon ( 5 genes $)$ & ATP dependent transport proteins \\
\hline & Tn 554 (ermA gene) & $\begin{array}{l}\text { ErmA ribosomal methylase (mediates } \\
\text { resistance to } \mathrm{MLS}_{\mathrm{B}} \text { antibiotics) }\end{array}$ \\
\hline & Tn 554 (ant 9 gene) & $\begin{array}{l}\text { O-nucleotidyltransferase } 9 \\
\text { (spectinomycin modifying enzyme) }\end{array}$ \\
\hline
\end{tabular}

ccr-cassette chromosome recombinase, $P B P$ - Penicillin Binding Protein, $M L S_{B}$-MacrolideLincosamide-Streptogranin B, Tn - Transposon

conventional and multiplex PCR, four structural types of SCCmec, designated type I-IV, were initially described but because the SCCmec chromosomal regions were found to be highly recombinogenic which results in a variety of SCCmec types, Chongtrakool et al ${ }^{34}$ have suggested a new proposal for the nomenclature for SCCmec.

\section{Clinical Significance of MRSA}

Mortality from invasive disease from both HA- and CA-MRSA infections is high. Recent meta analysis by Cosgrove et $\mathrm{l}^{35}$ showed higher mortality in patients with MRSA bacteramia when compared to MSSA bacteraemia. This was partly due to the fact that patients with MRSA infections had more comorbidities and were generally older than those with MSSA bacteraemia. In another study by Perovic et al, ${ }^{36} 33.3 \%$ of 105 patients with MRSA bacteraemia died within 14 days of admission, compared to $20.1 \%$ of 344 patients with MSSA bacteraemia ( $p=0.0048)$. Oxacillin, ofloxacin and rifampicin resistance, and admission into intensive care units were highly significant predictors of mortality in the study.

Because of the multi-resistant nature of MRSA, the choice of antibiotic treatment of MRSA infection is limited to few but potentially toxic drugs such as vancomycin. ${ }^{11}$ The emergence of MRSA strains with reduced vancomycin susceptibility and vancomycin resistance has further complicated therapy of MRSA infections as only few investigational drugs are currently on trial.

MRSA infection takes longer time to treat and prolongation of infection encourages nosocomial transmission of pathogen and disease oubreaks in hospitals. Prolonged hospital stay increase cost of treatment to individual, hospital and the government. Extensive eradication procedures needed to ensure that colonized or infected patients are completely free of the pathogen is very costly. ${ }^{37}$ There is also loss of 'manhour' at work leading to decrease productivity.

MRSA has capacity to acquire, in addition to multi-resistant genes, other genes that encode toxin production such as Panton-Valentine leukocidin (PVL), which causes pore formation on 
polymorphonuclear cells of the host and arginine catabolic mobile element (ACME), which inhibit polymorphonuclear cell production. Clones of such hyper-virulent MRSA strains in the United States (USA 300 or ST8-MRSAIV) and in Europe (ST80-MRSA-IV) carrying these toxin genes have been involved in community outbreaks of skin and soft tissue infections (SSTI), abscesses and severe cases of necrotizing pneumonia. ${ }^{38}$

\section{Laboratory Detection of MRSA}

Phenotypic detection of MRSA has been problematic ever since its discovery in the 1960s. Heterogenous expression of methicillin resistance complicates detection of these strains in clinical microbiology laboratories. Methods successful for other antibiotics can be insensitive for detection of methicillin resistance. Resistance can easily be missed if inappropriate or improperly stored â-lactam antibiotic is tested, if the incubation is too brief (e.g. 18 hours instead of 24 hours), if temperature of $37^{\circ} \mathrm{C}$ is used or if the inoculum is too low..$^{39}$ On the other hand, methods to enhance sensitivity in detection of methicillin resistance, such as increase salt concentration of media and prologed (48hours) incubation, can lead to erroneous categorization of susceptible strains as resistant. Genotypic detection of mecA gene or its product, PBP 2' (PBP2a) by immunoblot assay, is however now considered the 'gold standard' for MRSA confirmation.

\section{Phenotypic Methods of Detecting Methicillin Resistance}

The methods for detection of methicillin resistance most commonly used in the clinical laboratories and for which sufficient data are available to judge their reliability are the disk diffusion, broth dilution, agar screen, Etest and many of the several automated systems.

i. Disk diffusion susceptibility testing. This method, which has been proven reliable in detecting methicillin resistance, can be performed using $1 \mu \mathrm{g}$ oxacillin disk, $1 \mu \mathrm{g}$ nafcillin disk, $5 \mu \mathrm{g}$ methicillin disk and very recently $10 \mu \mathrm{g}$ or $30 \mu \mathrm{g}$ cefoxitin disk. ${ }^{16}$ Incubation temperatures of $30-35^{\circ} \mathrm{C}$ give similar result for oxacillin, methicillin and nafcillin though oxacillin gives the best standardized and reliable result because of its stability. ${ }^{40}$ The Clinical and Laboratory Standards Institute (formerly called National Committee for Clinical and Laboratory Standards) specifies optimum temperature of $35^{\circ} \mathrm{C}$ for testing of staphylococci to oxacillin ${ }^{15}$ and full 24 hours incubation. For cefoxitin, high accuracy has been found using incubation temperature not more than $36^{\circ} \mathrm{C}^{16}$ and 18 hours incubation time. Recommended culture medium for disk diffusion susceptibility testing is Mueller-Hinton (MH) agar although Iso-Sensitest and Mannitol salt agar (MSA) have been reliably used. The sensitivity of detection of methicillin resistance in MRSA with $1 \mu \mathrm{g}$ oxacillin or $5 \mu \mathrm{g}$ methicillin disk in unsupplemented $\mathrm{MH}$ agar at $35^{\circ} \mathrm{C}$ is $95-100 \% .^{40}$ One drawback of the disk diffusion test is that the use of standard inoculum $\left(10^{7} \mathrm{CFU}\right)$ may not detect some hetero-resistant MRSA strains. In this case, high-inoculum $\left(10^{9} \mathrm{CFU}\right)$ disk diffusion has been found useful in detecting these heteroresistant strains.

ii. Broth microdilution MIC susceptibility testing. The standard broth microdilution test uses bacterial inoculum of approximately $5 \times 10^{5} \mathrm{CFU} / \mathrm{ml}$ and cationsupplemented $\mathrm{MH}$ broth containing $2 \%$ sodium chloride ${ }^{15}$ to determine the minimum inhibitory concentration (MIC) of oxacillin for the isolate. Incubation is at $35^{\circ} \mathrm{C}$ for 24 hours and oxacillin, methicillin or nafcillin can be used but cephalosporins and cloxacillin should not be used because they give inaccurate results. Although addition of $5 \%$ $\mathrm{NaCl}$ may slightly improve detection of resistance; at this concentration, higher rates of borderline or falsely resistant results occur for susceptible strains. Incubation for 18 hours render the test too insensitive and because of $\beta$-lactamase effect, incubation for 48 hours is not recommended. ${ }^{41}$ In most studies, sensitivity of detecting methicillin resistance by this method exceed 95\% and specificity approaches $100 \%$.

iii. E-test (Epsilom-test) MIC method. In this method, an E-test strip (AB Biodisk, Solna, Sweden) containing graded concentration of $\beta$-lactam antibiotic is aseptically placed on an agar plate, which entire surface has been inoculated with a standardized inoculum (0.5 Mc Farland standard) of the bacterium. The agar plate is incubated for 18-24 hours at 35$37^{\circ} \mathrm{C}$ and the MIC is read as the point of intersection between edge of zone of inhibition and the E-test strip. Oxacillin E-test for detection of methicillin resistance in $S$. aureus has been standardized for use with $\mathrm{MH}$ agar supplemented with $2 \%$ $\mathrm{NaCl}$ and incubation at $35^{\circ} \mathrm{C}$ for full 24 hours but recently cefoxitin E-test strip, which has comparable sensitivity and specificity with oxacillin E-test, is performed with unsupplemented $\mathrm{MH}$ agar and incubation temperature of $35^{\circ} \mathrm{C}$ or $36^{\circ} \mathrm{C}$ for 18 hours. ${ }^{16}$ E-test method has been shown to have excellent correlation with broth microdilution and the agar screen method for the detection of MRSA.

iv. Agar screen method. This is one of the earliest reference methods used to define methicillin resistance in staphylococci. In this method, a bacterial suspension $\left(10^{4} \mathrm{CFU} / \mathrm{ml}\right)$ is inoculated or spotted onto agar containing a $\beta$-lactam antibiotic. Growth of any colony on this drugcontaining agar after 24 hours incubation is indicative of resistance. The most frequently used media is $\mathrm{MH}$ agar supplemented with $2-4 \% \mathrm{NaCl}$ containing $6 \mu \mathrm{g} / \mathrm{ml}$ oxacillin or $10 \mu \mathrm{g} /$ $\mathrm{ml}$ methicillin. The sensitivity of agar screen method for detection of MRSA approaches $100 \%$. Incubation for 48 hours is not recommended because $\beta$-lactamase producing susceptible $S$. aureus may grow after 24 hours. ${ }^{41}$ Even with several methodologies under various culture conditions, the 
sensitivity and specificity of this technique are consistently high and correlate well with other reference methods.

v. Population analysis profile. In this method, the proportion of heterogeneous cells in an overnight broth culture of a particular isolate is calculated on the basis of the ratio of colony-forming unit (CFU) growing on agar plates containing a range of concentrations of $\beta$ lactam antibiotic such as methicillin or oxacillin, to the number of CFU growing on drug-free agar plates after 24 or 48 hours incubation. By plotting the number of CFU at each concentration tested, it is possible to classify isolates as belonging to four expression classes, depending upon the degree of heterogeneity or homogeneity of methicillinresistant cells in the population. This method correlates well with the $m e c$ gene analysis and is a reference phenotypic method of detecting methicillin resistance.

vi. Automated systems. Several automated systems for detection of methicillin resistance, mostly based on broth microdilution methods, are in use. These include Autobac, Sceptor, AutoMicrobic and Vitek GPS-SA Card systems. ${ }^{42}$ Variable results have been reported regarding the accurate detection of methicillin resistance with these commercial kits due to changes in software over time, variations in reference methodology used and poor definition as to the relative distribution of isolates expressing homogenous and various degrees of heterogeneous resistance. Laboratories using automated systems should therefore use either a confirmatory reference method (e.g. disk diffusion, broth dilution, agar screen) or conduct a trial comparing automated system with a reference method to document accuracy for the strains present within a particular hospital or community.

vii. Phenotypic detection of MRSA directly from clinical sample. Selective culture media that have been used to isolate MRSA directly from clinical specimens containing mixed flora include mannitol salt agar (MSA) with different concentration of salts, with or without oxacillin or methicillin and soft salt mannitol agar cloxacillin (SSMAC) for rapid bedside screening for MRSA nasal carriage. Other media in use are $\mathrm{MH}$ agar supplemented with $4 \% \mathrm{NaCl}$, blood agar containing $5 \mathrm{mg} / \mathrm{L}$ oxacillin or $4 \mathrm{mg} / \mathrm{L}$ methicillin, and milk agar containing $2.5 \% \mathrm{NaCl}$ and $4 \mathrm{mg} / \mathrm{L}$ methicillin. Seroagglutination kits can also be used to rapidly screen and identify MRSA directly from clinical samples or presumptively from culture media prior to confirmation by disk diffusion, broth microdilution MIC or agar screen methods.

\section{Genotypic method of detecting methicillin resistance}

The 'gold standard' for MRSA detection/confirmation is one of the several genotypic methods for detecting the $m e c A$ gene that encodes the abnormal penicillin binding protein 2' (PBP 2') responsible for methicillin resistance. In the clinical laboratory, $m e c A$ gene can be detected using the three hours DNA hybridization probe. ${ }^{17}$ This is highly sensitive and specific and correlates with phenotypic susceptibility testing and other genotyping methods. However, the polymerase chain reaction (PCR) is now the most frequently used genotypic

Table3: Comparison of different methods for detecting methicillin resistance in Staphylococcus aureus

\begin{tabular}{lll}
\hline $\begin{array}{l}\text { Method } \\
\text { Phenotypic }\end{array}$ & Sensitivity & Specificity \\
\hline Disk diffusion* & High $(\geq 95 \%)$ & High $(95-100 \%)$ \\
Broth dilution & $\operatorname{High}(\geq 95 \%)$ & Very High $(100 \%)$ \\
Agar screen & High & Very High (reference method) \\
E-test* & High & High \\
Population analysis profile & Very High & Very High (reference method) \\
Automated system & Variable & Variable \\
Commercial sero-agglutination kits & Variable & Variable \\
Genotypic & High & Very High \\
DNA hybridization probe & Very High & Very High (gold standard \\
mecA gene PCR & & method) \\
\hline
\end{tabular}

* Oxacillin and cefoxitin are recommended method to identify and confirm MRSA in clinical sample or culture media. This is done by amplifying internal fragments of $m e c A$ gene using a pair of closely spaced oligonucleotides (primers). Several PCR protocols are available for amplification and this procedure remains the confirmatory reference methodology for MRSA.

\section{Recent Epidemiological Typing Methods of MRSA}

It is sometimes desirable to separate strains of $S$. aureus into types or groups because of the ubiquitous nature of the organism. This is usually indicated to detect outbreak of $S$. aureus infections in hospitals as well as in the community. For good understanding of the population and evolutionary biology of S. aureus (MRSA and MSSA), and to determine the origin, spread and relatedness of MRSA (or MSSA) clones described by different laboratories, isolates of this species need to be characterized unambiguously. Typing methods should have high and relevant discriminatory power and typeability, good reproducibility, applicability to all organisms of interest, ease of use, produce data that can be easily transferred between laboratories or presented in published work and be cost effective. ${ }^{43}$

Many of the conventional epidemiological typing methods that have been used for MRSA such as serotyping, biotyping, antibiotic 
Table 4: Methods for Fingerprinting MRSA

\begin{tabular}{ll}
\hline Conventional Method & Molecular Methods \\
\hline Serotyping & Plasmid fingerprinting \\
Biotyping & Pulse field gel electrophoresis of genomic DNA \\
Antibiogram & Ribotyping (16s rRNA) \\
SDS-PAGE of surface proteins & Repetitive element PCR \\
Multilocus enzyme electrophoresis & Multilocus sequence typing \\
Bacteriophage typing & SCCmec typing \\
& spa typing \\
& coa typing \\
\hline
\end{tabular}

SDS-PAGE - sodium dodecy sulphate-polyacrylamide gel electrophoresis

susceptibility profiling (antibiogram), surface protein electrophoresis, multilocus enzyme electrophoresis and bacteriophage typing, do not meet many of these criteria. These typing methods are no longer in use with the exception of bacteriophage and zymotyping, which are still being used by some large reference laboratories around the world for typing S. aureus, and serotyping, which has been limited to epidemiological surveillance of Salmonella species.

In recent times therefore, typing methods for study of local and global epidemiologies of MRSA have shifted from these conventional techniques to molecular methods, which offer advantages in typeability, discrimination and reproducibility. Molecular typing methods used to characterize MRSA strains include plasmid fingerprinting, pulse field gel electrophoresis (PFGE) of SmaI digested genomic DNA, ribotyping and PCR-based amplification/sequencing of target genes such as repetitiveelement PCR, multilocus sequence typing (MLST), SCCmec typing and staphylococcal protein A (spa) typing.

i. Plasmid fingerprinting. This is a strong tool for bacterial strain identification and surveillance of nosocomial and community acquired infections. The diversity and stability of plasmids carried by MRSA strains during outbreaks, ${ }^{44}$ the ease of plasmid detection by gel electrophoresis from crude bacterial lysate and the reproducibility of detection method made plasmid fingerprinting a powerful epidemiological typing tool for MRSA. In fingerprinting, plasmids are first extracted from lysed bacteria and then subjected to restriction enzyme digest. Fragments are then resolved on agarose gel as bands and visual comparison made between different isolates to determine their relatedness. In Nigeria, Taiwo et $a l^{45}$ used restriction enzyme analysis of plasmid (REAP) DNA to characterize an MRSA oubreak in University of Ilorin Teaching Hospital in 2001. The investigators were able to characterize an epidemic MRSA strain with a unique REAP profile that was responsible for a short outbreak of infection in the hospital that year. The shortfall of this method is that some MRSA strains lack plasmids while in some, the plasmids are unstable and addition or lack of a plasmid may not necessarily designate a different strain. Plasmid fingerprinting has been largely replaced by more discriminatory genotyping methods.

ii. Pulse field gel electrophoresis (PFGE). This is the most commonly used method for studying local or short term $S$. aureus epidemiology. It has proven very successful in the investigation of nosocomial outbreaks, and has also been used to identify MRSA clones that have a particular ability to cause major outbreaks and to spread nationally and internationally (epidemic MRSA clones; EMRSA). PFGE involves embedding organism in agarose, lysing the organism in situ, and digesting the chromosomal DNA with restriction enzymes that cleave infrequently. ${ }^{46}$ Slices of agarose containing the chromosomal DNA fragments are inserted into the wells of an agarose gel and the restriction fragments are resolved into a pattern of discrete bands in the gel by an apparatus that switches the direction of the current according to a predetermined pattern. The DNA restriction patterns of the isolates are then compared with one another to determine their relatedness. The commonly used restriction enzyme is Sma-I but additional enzymes could be used to increase the discriminatory power of the PFGE. This include enzymes such as $S a I$, CspI, ApaI, NotI, XbaI, SpeI, SalI, BglII, SfiI, RsrII, AseI, Eag, SacII, NarI, NaeI and Sse83871. ${ }^{46}$

Interpretive criteria for bacterial strain typing using PFGE has been set by Tenover et $a l^{46}$ and applied to non-outbreak situations to track the national and international dissemination of $S$. aureus clones. Multicenters studies using PFGE are now possible due to recent advances in the standardization of electrophoretic conditions. ${ }^{47}$ The major demerits of PFGE are that it may be too discriminatory for other than local or short-term epidemiological analysis, the arbitrary nature of the interpretive criteria and occasional requirement for subjective analysis of complex band patterns.

iii. Multilocus sequence typing (MLST). This is an investigatory tool in many studies of $S$. aureus evolution and epidemiology, and has had a large impact on the field of bacterial strain typing. It has advantage over PFGE as a reference typing method because of the unambiguous nature of the DNA sequences, which can be stored easily along with the corresponding clinical information on each isolate (it is portable) in Internet-linked databases ( $S$. aureus MLST website: http://www.mlst.net currently contain information on 2,276 human and animal $S$. aureus isolates from over 40 different countries). MLST characterize bacterial isolates on the basis of the 
sequences of approximately 450-bp internal fragments of seven housekeeping genes. ${ }^{48}$ Seven primer pairs are designed to amplify the internal fragment of each gene (about $500 \mathrm{bp}$ ), which allows accurate sequencing of approximately 450-bp fragment of each gene.

For each gene fragment, the different sequences are assigned as distinct alleles, and each isolate is defined by the alleles at each of the seven housekeeping loci - the allelic or sequence type (ST). As there are many alleles at each of the seven loci, isolates are highly unlikely to have identical allelic profiles by chance. Isolates with the same allelic profile or sequence type (ST) can be assigned as members of the same clone. STs sharing $100 \%$ genetic identity in at least five of seven MLST loci are grouped into a clonal complex (CC) named after its presumed ancestral genotype. The commonly used housekeeping genes for $S$. aureus are $\operatorname{arc} C$ (carbamate kinase), aroE (shikimate dehydrogenase), glpF (glycerol kinase), gmk (guanylate kinase), pta (phosphate acetytransferase), tpi (triose phosphate isomerase) and yqiL (acetylcoenzyme A acetyltransferase). The demerits of MLST is that it is not widely applicable as other methods for high volume analysis of MRSA due to the high cost of DNA sequencing. MLST requires seven PCRs plus fourteen DNA sequencing reactions per isolate.

iii. SCCmec typing. The SCCmec chromosomal region in MRSA isolates is known to be highly recombinogenic resulting in a variety of SCCmec types. ${ }^{34}$ The structural types of SCC and the class of mec region (A or $\mathrm{B}$ ) is determined by conventional or multiplex PCR. SCCmec typing requires an everchanging number of primers as new alleles.

iv. MLST/SCCmec typing. This is now the 'gold standard' typing technique that is being used for international nomenclature of MRSA clones and this has been accepted by the International Union of Microbiological Societies subcommittee on $S$. aureus typing e.g. the UK EMRSA-15 clone under the MLST/SCCmec typing scheme will be referred to as ST22-MRSAIV (MLST ST 22, MRSA SCCmec type IV), USA 300 clone will be referred to as ST8-MRSA-IV etc. This scheme allows the efficient worldwide tracking and surveillance of MRSA clones.

v. Spa typing. The staphylococcal protein A typing method is a rapid sequence-based approach to accurately characterize MRSA. It is discriminatory, easy to use and portable. ${ }^{49}$ In this typing method, the short sequence repeat region of the spa gene is sequenced and the sequence obtained is compared to those found in the Internet accessible spa sequence database Spaserver (http://www.ridom.de/ spaserver/

vi. Combined typing approach. This is the approach recommended by the EU-funded Harmony project ${ }^{50}$ for more widespread epidemiological typing of MRSA. In this approach, PFGE and/or spa typing is initially used to determine genetic relatedness of different isolates and MLST/SCCmec typing is then used for further characterization of representative isolates of each genotype and assignment into clonal groups.

\section{What Needs to be Done in Nigeria}

Although reports of MRSA colonization and infections from Nigeria and other African countries (except South Africa) are very few in the literature, this does not equate to low prevalence of this infection. Only few institutions carry out limited (unsustained) survey of MRSA and most clinicians are unaware of the attributable mortality or morbidity due to MRSA infection (personal communication). The clinical significance of MRSA is hence overlooked. Two studies from the same institutions ${ }^{25,26}$ in Nigeria have reported MRSA strains resistant to vancomycin without any history of exposure to vancomycin. The mechanism of resistance of these MRSA strains to vancomycin is not known as all cases of vancomycin resistance reported in literature so far are from patients who have been on prolonged vancomycin therapy. It will be interesting to know the mechanism of vancomycin resistance in what may appear to be an MRSA strain indigenous to Nigeria.

Because most strains of MRSA in Nigeria are still sensitive to the fluoroquinolones, ${ }^{28,36,42,46}$ there may be no percieve real danger of serious infections since several fluoroquinolones brand are available in the country. However, there is need for active surveillance of hospitalized patients and heath care personnel for MRSA by the clinical and laboratory departments to identify potential sources of outbreaks. All patients admitted into hospital must be screened for MRSA and new staff should be screened for MRSA carriage. There should be isolation and treatment of all

Table 5: Comparison of four common molecular typing methods for MRSA

\begin{tabular}{|c|c|c|c|c|c|c|c|}
\hline Methods & $\begin{array}{l}\text { Discriminatory } \\
\text { Power }\end{array}$ & Typeability & Reproducibility & Applicability & Technicality & $\begin{array}{l}\text { Data } \\
\text { Transferability }\end{array}$ & $\begin{array}{l}\text { Cost } \\
\text { Effectiveness }\end{array}$ \\
\hline $\begin{array}{l}\text { Plasmid } \\
\text { fingerprinting }\end{array}$ & Moderate & Low & Reproducible & Limited & Easy & Not Easy & Yes \\
\hline PFGE & Very High & High & Reproducible & Wide & Difficult & Not Easy & Expensive \\
\hline MLST & Very High & High & Reproducible & Wide & Difficult & $\begin{array}{l}\text { Easy via the } \\
\text { Internet }\end{array}$ & Very Expensive \\
\hline Spa typing & High & High & Reproducible & Wide & Less difficult & $\begin{array}{l}\text { Easy via the } \\
\text { Internet }\end{array}$ & Less Expensive \\
\hline
\end{tabular}


colonized or infected staff and they must be prevented from handling patients until all organism have been eradicated from them. This is a measure that has been applied in Australia to control the spread of MRSA infections and outbreaks.

Clinical microbiology laboratories in Nigeria must begin to routinely screen all clinical samples received in the laboratory for MRSA and report to infection control unit of the institution, of any positive case; colonized or infected. In addition, there must be coordination of efforts among public health authorities about investigation and reporting of an outbreak in Nigerian hospitals. There is urgent need for a public health reference laboratory saddle with the responsibility of establishing a national MRSA database for Nigeria through systematic surveillance, identification and confirmation of all suspected MRSA isolates sent to it from various health care institutions and assignment into clonal groups.

There is also need for vigilance in the enforcement of infection control measures that can limit emergence of more resistant clones of MRSA and spread of infection in the hospital and community, such as rational prescription of antibiotic, handwashing, disinfection and sterilization.

\section{REFERENCES}

1. Projan SJ, Novick RP. The molecular basis of pathogenicity. In: Crossley $\mathrm{KB}$, Archer GL, eds. The staphylococci in human diseases, New York, Churchill Livingstone: 1997: 55-81.

2. Jevon MP. 'Celbenin'-resistant staphylococci (letter). Br Med J 1961; 1: 24-25.

3. Parker MT, Hewitt MJH. Methicillin resistance in Staphylococcus aureus. Lancet. 1970; 1: 800-804.

4. Haley RW, Hightower AW, Khabbaz RF. The emergence of methicillinresistant Staphylococcus aureus in United States hospitals. Ann Intern Med 1982; 97: 297-308.

5. Voss A, Doebbeling BN. The world wide prevalence of MRSA. Int J Antimicrob Agents. 1995; 5: 101-106

6. Sjostrom JE, Lofdahl S, Philipson L. Transformation reveals a chromosomal locus of the gene(s) for methicillin resistance in Staphylococcus aureus. $J$ Bacteriol. 1975; 123: 905-915.
7. Katayama Y, Ito T, Hiramatsu K. A new class of genetic element, staphylococcus cassette chromosome mec (SCCmec), encodes methicillin resistance in Staphylococcus aureus. Antimicrob Agents Chemother. 2000; 44: 1548-1555.

8. Hartman BJ, Tomasz A. Low-affinity penicillin-binding proteins of â-lactam resistance in Staphylococcus aureus. J Bacteriol. 1984.; 158: 513-516.

9. Kuroda M, Ohta T, Uchiyama I, Baba T, Yuzawa H, Kobayashi I, et al. Whole genome sequencing of meticillinresistant Staphylococcus aureus. Lancet. 2001; 357: 1225-1240.

10. National Nosocomial Infections Surveillance System. National Nosocomial Infections Surveillance System report, data summary from January 1990 - May 1999. Am J Infect Control. 1999; 27: 520-532.

11. Watanakunakorn C. Treatment of infections due to MRSA. Ann Intern Med. 1982; 94: 785-788.

12. Saravolatz LD, Pohlod DJ, Arking LM. Community acquired methicillinresistant Staphylococcus aureus infections: a new source for nosocomial outbreaks. Ann Intern Med. 1982; 97: 325-329.

13. Centers for Disease Control and Prevention. Four paediatric deaths from community-acquired methicillinresistant Staphylococcus aureus Minnesota and North Dakota, 19971999. MMWR Morb. Mortal. Wkly. Rep. 1999; 48: 707-710.

14. Lindenmayer JM, Schoenfeld S, O'Grady R, Carney JK. Methicillinresistant Staphylococcus aureus in a high school wrestling team and surrounding community. Arch Intern Med. 1998; 158: 895-899.

15. Clinical and Laboratory Standards Institute. Performance standards for antimicrobial susceptibility testing. 15th informational supplement M100S15. Clinical and Laboratory Standards Institute, Wayne, PA, 2005.

16. Skov R, Smyth R, Larsen AR, BolmstrÕm A, Karlsson A, Mills K, et al. Phenotypic detection of methicillin resistance in Staphylococcus aureus by disk diffusion testing and E-test on Mueller-Hinton agar. J Clin Microbiol. 2006; 44: 4395-4399.

17. Skov R, Palleson LV, Poulsen RL, Espersen F. Evaluation of 3 new hours hybridization method for detection of the mecA gene in Staphylococcus aureus and the correlation to existing genotypic and phenotypic susceptibility testing methods. J Antimicrob Chemother. 1999; 43: 467-475.

18. Shopsin B, Kreiswirth BN. Molecular epidemiology of methicillin-resistant Staphylococcus aureus. Emerg Infect Dis. 2001; 7: 323-326.

19. Bell JM, Turnidge JD. High prevalence of oxacillin-resistant Staphylococcus aureus isolates from hospitalized patients in Asia-Pacific and South Africa: results from SENTRY antimicrobial surveillance program 1998-1999. Antimicrob Agents Chemother. 2002; 46: 879-881.

20. American Journal of Infection Control. National Nosocomial Infections Surveillance (NNIS) System Report, data summary from January 1992 to June 2002, issued August 2002. Am J Infect Control. 2002; 30: 458-475.

21. Hiramatsu K, Hanaki H, Ito T, Yabuta K, Oguri T, Tenover FC. Methicillinresistant Staphylococcus aureus clinical strain with reduced vancomycin susceptibility. J Antimicrob Chemother. 1997; 40: 135-136.

22. Ploy MC, Grelaud C, Martin C, de Lumley L, Denis F. First clinical isolate of vancomycin-intermediate Staphylococcus aureus in a French hospital (letter). Lancet. 1998; 351: 1212.

23. Smith TL, Pearson ML, Wilcox KR. Emergence of vancomycin resistance in Staphylococcus aureus. N Engl J Med. 1999; 340: 493-501.

24. Michigan Department of Community Health (MDCH). Second Michigan VRSA case: 3 March 2005. [Online] http://www.michigan.gov/documents/ VRSA_Feb05_118391_7.pdf

25. Olayinka BO, Olayinka AT, Onaolapo JA, Olurinola PF. Pattern of resistance to vancomycin and other antimicrobial agents in staphylococcal isolates in a University Teaching Hospital. Afr J Clin Exper Microbiol. 2005; 6: 21-27.

26. Onolitola OS, Olayinka BO, Salawu MJ, Yakubu SE. Nasal carriage of methicillin-resistant Staphylo-coccus aureus with reduced vancomycin susceptibility (MRSA-RVS) by healthy adults in Zaria, Nigeria. J Trop Microbiol Biotechnol. 2007; 3: 19-22.

27. Rotimi VO, Orebanjo O, Banjo TO, Nwobu R, Onyenefa PI. Occurrence and antibiotic susceptibility profile of methicillin-resistant Staphy-lococcus aureus in LUTH Lagos. Centr Afr J Med. 1987; 33: 95-98.

28. Okesola AO, Oni AA, Bakare RA. Prevalence and antibiotic suscepti-bility pattern of MRSA in Ibadan, Nigeria. $J$ Hosp Infect. 1999; 41: 74-75. 
29. Ikeh EI. Methicillin-resistant Staphylococcus aureus (MRSA) at Jos University Teaching Hospital. Afr J Clin Exper Microbiol. 2003; 4: 52-55.

30. Taiwo SS, Onile BA, Akanbi II AA. Methicillin-resistant Staphylococcus aureus (MRSA) isolates in Ilorin. Afr J Clin Exper Microbiol. 2004; 5: 189-197

31. Taiwo SS, Fadiora SO, Fayemiwo SA. High antimicrobial resistance among bacterial isolates of blood stream infections in a Nigerian University Teaching Hospital. World J Microbiol Biotechnol. 2008; 24: 231-236.

32. Matsuhashi M, Song MD, Ishino F. Molecular cloning of the gene of a penicillin binding protein supposed to cause high resistance to beta-lactam antibiotics in Staphylococcus aureus. J Bacteriol. 1986; 167: 975-980.

33. Kreiswirth B, Kornblum J, Arbeit RD, Eisener W, Maslow JN, McGeer A, et al. Evidence for clonal origin of methicillin resistance in Staphylococcus aureus. Science. 1993; 259: 227-230.

34. Chongtrakool P, Ito T, Ma XX, Kondo Y, Trakulsomboon S, Tiensasitorn C, et al. Staphylococcal cassette chromosome mec (SCCmec) typing of methicillin-resistant Staphylococcus aureus strains isolated in 11 Asian countries: a proposal for a new nomenclature for SCCmec elements. Antimicrob. Agents Chemother. 2006; 50: 1001-1012.

35. Cosgrove SE, Sakoulas G, Perencevich EN, Schwaber MJ, Karchmer AW, Carmeli Y. Comparison of mortality associated with methicillin-resistant and methicillin-susceptible Staphylococcus aureus bacteraemia: a meta analysis. Clin. Infect. Dis. 2003; 36: 53-59.

36. Perovic O, Koonrnhof H, Black V, Moodley I, Duse A, Galpin J. Staphylococcus aureus bacteraemia in two academic hospitals in Johannesburg. South Afr Med J. 2006; 96: 714-717.

37. Rubin RJ, Harrington CA, Poon A, Dietrich A, Greene JA, Moiduddin A. The economic impact of Staphylococcus aureus infection in New York City hospitals. Emerg Infect Dis. 1999; 5: 9-17.

38. Johnson JK, Khole T, Shurland S, Kreisel K, Stine CO, Roghmann M. Skin and soft tissue infections caused by methicillin-resistant Staphylococcus aureus USA300 clone. Emerg Infect Dis. 2007; 13: 1195-1200.

39. Thornsberry C, Caruthers JQ, Baker $\mathrm{CN}$. Effect of temperature on the in vitro susceptibility of Staphylococcus aureus to penicillinase-resistant penicillins. Antimicrob Agents Chemother. 1973; 4: 263-269.

40. Boyce JM. Re-evaluation of the ability of the standardized disk diffusion test to detect methicillin-resistant strains of Staphylococcus aureus. J Clin Microbiol. 1984; 19: 813-819.

41. McDougal LK, Thornsberry C. The role of $\beta$-lactamase in staphylococcal resistance to penicillinase-resistant penicillin and cephalosporin. J Clin Microbiol. 1986; 23: 832-839.

42. Putland RA, Guinness MDG. Autobac susceptibility testing of methicillinresistant and susceptible Staphylococcus aureus isolated in an Australian hospital. J Clin Microbiol. 1985; 22: 822-827.

43. Struelens MJ. Consensus guidelines for appropriate use and evaluation of microbial epidemiologic typing systems. Clin Microbiol Infect. 1996; 2: 2-11.

44. Zuccarelli AI, Roy I, Harding GP. Diversity and stability of restriction enzyme profiles of plasmid DNA from methicillin-resistant Staphylococcus aureus. J Clin Microbiol. 1990; 28: 97102.
45. Taiwo SS, Bamidele M, Omonigbehin EA, Akinsinde KA, Smith SI, Onile BA, et al. Molecular epidemiology of methicillin-resistant Staphylococcus aureus in Ilorin, Nigeria. West Afr J Med. 2005; 24: 100-106.

46. Tenover FC, Arbeit RD, Goering RV, Mickelsen PA, Murray BE, Persing $\mathrm{DH}$, et al. Interpreting chromosomal DNA restriction patterns produced by pulse field gel electrophoresis: criteria for bacterial typing. J Clin Microbiol. 1995; 33: 2233-2239.

47. Chung MH, de Lencastre P, Matthews P, Tomasz A, Adamsson I, Aries de Sousa M, et al. Molecular typing of methicillin-resistant Staphylococcus aureus by pulse field gel electrophoresis: comparison of results obtained in a multi-laboratory effort using identical protocols and MRSA strains. Microb Drug Resist. 2000; 6: 189-198.

48. Enright MC, Day NPJ, Davies CE, Peacock SJ, Spratt BG. Multilocus Sequence Typing for characterization of Methicillin-Resistant and MethicillinSusceptible clones of Staphylococus aureus. J Clin Microbiol. 2000; 38: 1008-1015.

49. Shopsin B, Gomez M, Montgomery SO, Smith DH, Waddington M, Dodge DE, et al. Evaluation of protein A gene polymorphic region DNA sequencing for typing of Staphylococcus aureus strains. J Clin Microbiol. 1999; 37: 3556-3563.

50. Cookson BD, Robinson DA, Monk AB, Murchan S, Deplano A, Ryck R, et al. Evaluation of molecular typing methods in characterizing a European collection of epidemic methicillin-resistant Staphylococcus aureus strains: the HARMONY collection. J Clin Microbiol. 2007; 45: 1830-1837. 